\title{
Review
}

\section{Molecular markers in prostate cancer. Part II: potential roles in management}

\author{
Sachin Agrawal, Krishnaji P. Patil, William D. Dunsmuir \\ Department of Urology, St Peters Hospital, Chertsey KT16 OPZ, UK
}

\begin{abstract}
Predicting treatment responses in advanced prostate cancer ( $\mathrm{PCa}$ ) currently centres on prostate-specific antigen (PSA) kinetics and on being able to visualize measurable changes in imaging modalities. New molecular markers have emerged as potential diagnostic and prognostic indicators; these were summarized in Part I of this review in the Asian Journal of Andrology. A number of molecular markers are now being used to enhance PCa imaging and staging. However, management options for advanced and hormone-resistant PCa (HRPC) are limited and additional therapeutic options are needed. Molecular markers have been proposed as potential therapeutic targets using gene therapy and immunomodulation. Additionally, markers identified in early PCa and precursor lesions may offer novel targets for chemoprevention and vaccine development. This review summarizes the current advances regarding the roles of these markers in the management of PCa.
\end{abstract}

Asian Journal of Andrology (2009) 11: 22-27. doi: 10.1038/aja.2008.23; published online 1 December 2008.

Keywords: genetics, management, molecular, prostate cancer

\section{Introduction}

Managing advanced prostate cancer $(\mathrm{PCa})$ is challenging, and the median survival in hormone-resistant PCa (HRPC) is still less than 2 years $[1,2]$. Taxanebased agents are the main chemotherapeutic options for HRPC, and molecular markers have been identified in their mechanism of action and seems to involve induction of apoptosis and inactivation of Bcl-2 [2]. The advent of new PCa molecular markers and the identification of genetic loci allow for the development of new therapeutic strategies, with additional applications including chemoprevention and targeted imaging. Research in these fields is summarized in Table 1 [2-38].

\section{Molecular imaging}

The use of molecular markers for direct imaging may help to detect $\mathrm{PCa}$, micro-metastases and $\mathrm{PCa}$ precur-

Correspondence to: Mr Sachin Agrawal, Department of Urology, St. Peters Hospital, Chertsey KT16 0PZ, UK.

Fax: +44-19-3272-2640 E-mail: agrawalsachin@hotmail.com

Received: 3 October 2008 Accepted: 10 October 2008

Published online: 1 December 2008 sor lesions at an early stage. Non-invasive imaging techniques that identify areas of tissue hypoxia have been described using magnetic resonance imaging or radio-labelled 2-nitro-imidazoles with positron emission tomography (PET). The ability to label areas of hypoxia or molecular change may offer potential therapeutic applications. Labelled agents could be used in conjunction with an appropriate sensitizing drug and precision intensity-modulated radiotherapy to guide treatment [35]. Molecular imaging has also been used to improve PCa staging. Currently, HSV1-tk is the most common reporter gene used with PET; it has also been used in antiviral suicide gene therapy $[22,39]$. Other markers include the sodium iodide symporter (NIS). Overall, molecular imaging may help to aid disease staging, guide treatment and offer the additional potential for monitoring therapeutic outcomes [22].

\section{Chemoprevention}

Targeting and modulating molecular markers identified in $\mathrm{PCa}$ precursor lesions, such as prostatic intraepithelial neoplasia (PIN) and proliferative inflammatory atrophy (PIA), offer the potential for chemoprevention, along with 
the ability to monitor the outcomes. Current research has focused on the modulation of serum hormones with $5-\alpha-$ reductase inhibitors (PCPT and REDUCE trials) [40, 41]. PIN has been used as a biomarker for chemoprevention with Toremifene, a selective oestrogen receptor modulator. This trial examined 514 men with HGPIN, in whom use of toremifene resulted in a $48 \%$ reduction of $\mathrm{PCa}$ incidence at 12 months, compared with placebo treatment $(P=0.05)$ [42]. Synthetic retinoids such as $N$-(4-hydroxyphenyl)retinamide (4-HPR) have also been used in animal models to demonstrate a reversal of the tumour's malignant characteristics and a decreased PCa incidence. However, a subsequent phase II study reported an increase in $\mathrm{PCa}$ incidence and was stopped [42].

\section{Prostate cancer vaccines}

Gene vaccines based on identified markers have been used in clinical trials. The PROSTVAC vaccine takes advantage of a genetically engineered, recombinant vaccinia virus that expresses the prostate-specific antigen (PSA) gene. Several early studies have shown PROSTVAC to be safe and well tolerated, leading to stable disease in patients for up to 19 months. Phase II and III (PARADIGM) studies are currently underway [10]. Prostate specific cell antigen (PSCA)-based vaccines have been under trial in a Pca-prone, transgenic-adenocarcinoma-mouse-prostate (TRAMP) mice model having PIN. PSCA-vaccinated TRAMP mice showed a $90 \%$ survival rate at 12 months compared with $0 \%$ in the control mice [43].

\section{Gene therapy}

A number of gene-modulation strategies exist, including the use of DNA/RNA vectors, antisense oligonucleotides, suicide/pro-apoptotic/anti-angiogenic genes and corrective gene therapy $[9,10,22]$.

DNA vectors can be transferred to a cell using an adenovirus (Ad), which transduces target cells efficiently even during cellular quiescence. However, the virus carries a low potential for inducing oncogenesis. RNA viral vectors are designed to target specific cells and to be replication deficient; examples include a retrovirus and a lentivirus. However, low transduction rates, dependence on cell division and rapid inactivation by human complement may limit their use in patients [9]. Antisense oligonucleotides are nucleic acid sequences considered to bind to oncogenic DNA in a manner that prevents mRNA transcription. This type of therapy has been used for c-MYC and Bcl-2 (Table 1).

Suicide gene therapy involves transduction of a suicide gene, followed by administration of a prodrug. The prodrug is converted to a toxic metabolite that induces tumour cell death by suicide gene-related products. Phase
I studies have investigated the use of systemic ganciclovir with a replication-deficient Ad, Ad-HSV-tk (herpes simplex virus type 1 thymidine kinase adenovirus). Results included a low toxicity with $>50 \%$ reduction of PSA in some patients $[9,39]$ and a significantly prolonged median PSA doubling time, increasing from 2.9 to 6.2 months $(P=0.041)$ [44]. Escherichia coli nitroreductase (NTR)/HSP 70 is thought be another promising cytotoxic/ immunomodulatory gene $[22,45]$. Pro-apoptotic Ad vector gene strategies aim to introduce tumour necrosis factor genes into target cells, which could include Fas ligand and tumour necrosis factor-related apoptosisinducing ligand (TRAIL) [22]. Further examples include melanoma differentiation associated gene-7/interlukin24 (mda-7/IL-24) and the RTVP-1 gene (related to testisspecific, vespid and pathogenesis protein) [22].

Oncolytic gene therapy is based on viral cytotoxity that is secondary to conditional viral replication within tumour cells, where this process induces cell lysis. The strategy employs tissue-specific promoters to direct viral expression and replication towards specific cells. One way that this strategy could be accomplished is through the control of Ad proteins E1A and E1B [22]. CG7870 Ad (previously CV787) is being evaluated in phase I/IIa trials in combination with docetaxel and has resulted in a mean PSA reduction of $44 \%$ in HRPC [9]. Murine osteocalcin (OC) promoters have also been used to restrict E1A (Ad OC-E1A virus) to the prostatic epithelium and osseus metastasis. This study was performed in mice and the results indicated undetectable PSA levels and a $40 \%$ cure, with no evidence of skeletal metastasis [22, 23]. Current oncolytic gene therapy phase I/II trials have been reviewed and are promising, but they require further evaluation $[9$, 22]. Corrective gene therapy aims to repair or replace defective genes. A replication-deficient Ad containing wildtype p53 injected intra-prostatically has been under trial. The tumour size was reduced by $25 \%$ in 3 of 17 cases [10].

\section{Immunomodulation}

PCa immunotherapy aims to induce antibody and/ or cytotoxic $\mathrm{T}$ lymphocyte (CTL) immune responses with cytokines and interleukins. Two mechanisms exist for this type of therapy. Active or direct immune system stimulation uses autologous dendritic cells, whereas the passive creation of immune cells involves the administration of monoclonal antibodies to specific cancer receptors [9]. Dendritic cells are harvested by leukapheresis. Targets include growth factor receptors and components of various signalling pathways. Granulocyte-macrophage colony-stimulating factor (GM-CSF) is a cytokine that promotes dendritic cell uptake of tumour antigens by regulating macrophages, granulocytes and monocytes [46]. In phase II trials, GMCSF-secreting vaccines using allogenic PCa cell lines 


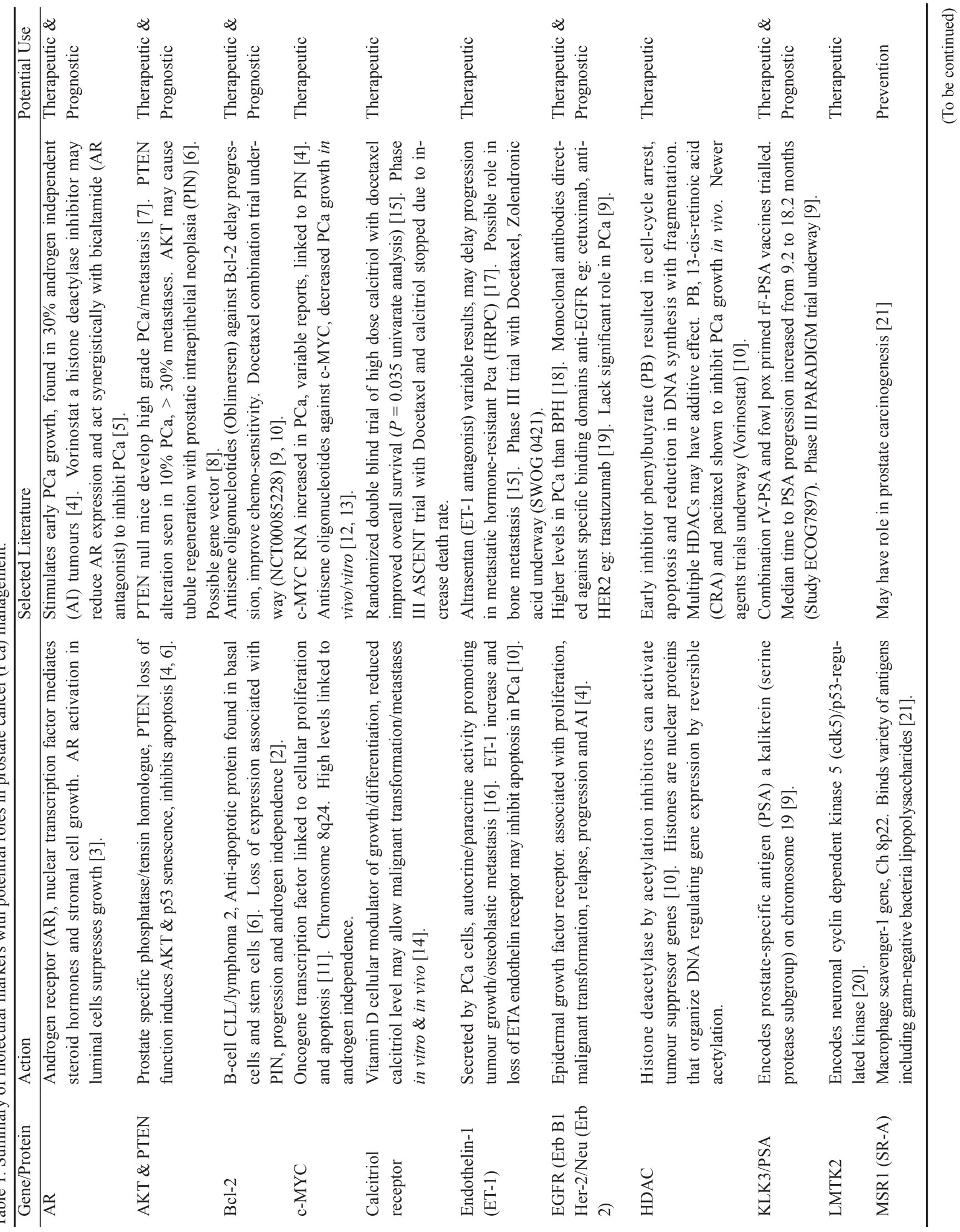




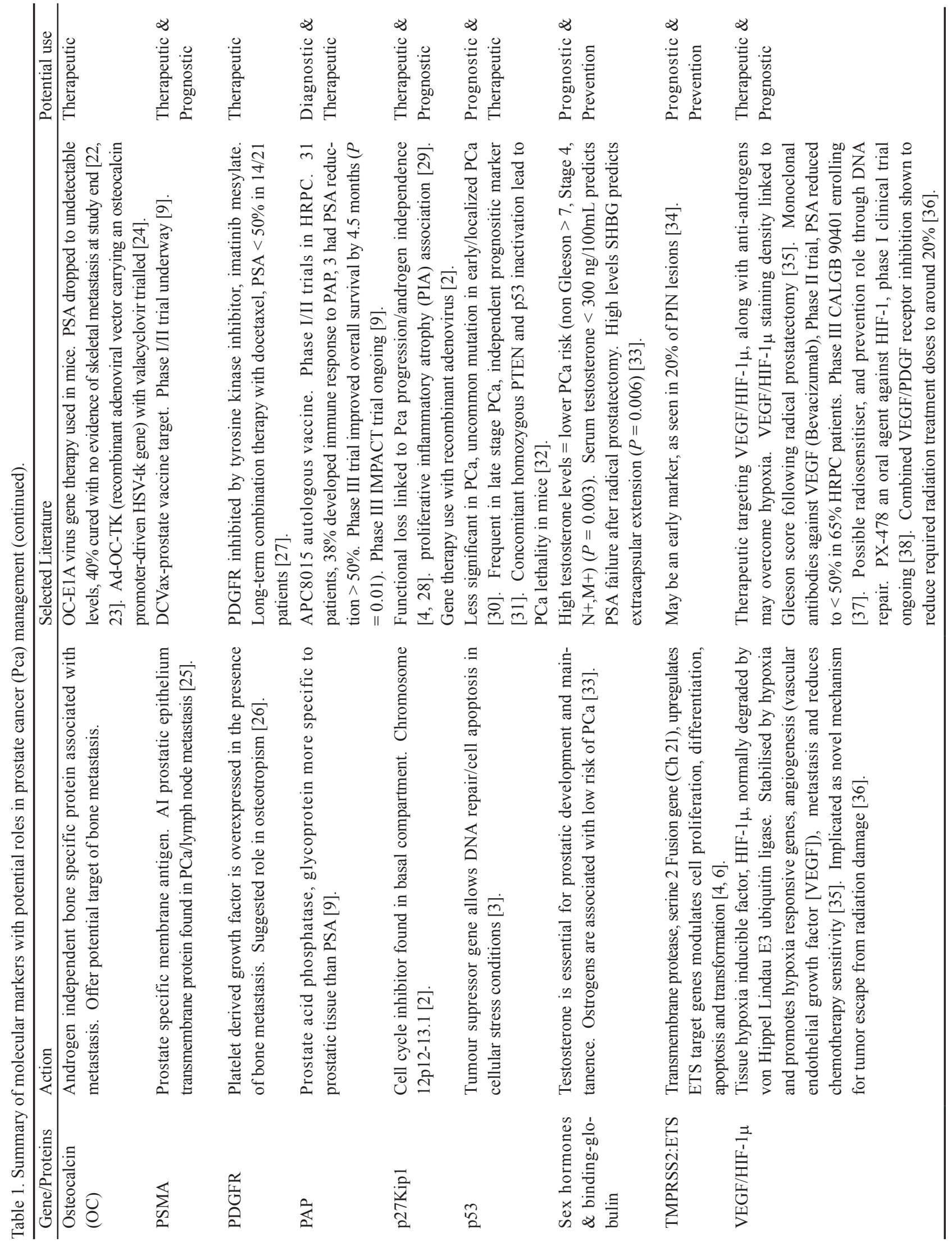


(GVAX vaccines) have improved the median survival of HRPC from 18 to 26.2 months, compared with patients treated with docetaxel. Phase III trials were initiated (Cell Genesys). VITAL I has been completed with interim analysis, and the study is continuing. However, VITAL II has been stopped because of an imbalance in deaths between the two groups. Further examples of autologousdendritic cells pulsed with specific peptides include DCVax-prostate vaccine (prostate specific membrane antigen [PSMA] peptides) and Sipuleucel-T (PA2024, a PAP /GM-CSF recombinant protein). A phase III study for Sipuleucel-T in 127 men with HRPC did not alter the time to progression but significantly increased the median survival compared with a placebo. At 3 years, $34 \%$ and $11 \%$ of men were alive in the Sipuleucel-T and placebo groups, respectively. However, a possible increase in cerebrovascular events was reported [10, 47].

Down-regulating T-cell responses to self-antigens may offer the potential to boost immunotherapy agents. A key inhibitor of cytotoxic T-cells is the cytotoxic T-lymphocyte antigen-4 (CTLA4) molecule (CD152). Anti-CTLA4 therapy has been used in combination with immunotherapy, and this course of action has been shown to enhance rejection of tumour cells. However, unwanted autoimmune side effects may be a potential obstacle. Phase II trials involving anti-CTLA4 therapy are underway [10]. Overall, immunomodulation offers promise but requires further evaluation.

\section{Combination therapy}

Given the multiple genetic markers identified in $\mathrm{PCa}$ development, a combination approach to therapy may improve the outcomes even more than treatment with one agent alone. Current strategies under investigation include the combination of multiple molecular techniques or molecular agents with conventional chemotherapy or radiotherapy. Examples include cytoreductive strategies (suicide genes/oncolytic gene therapy), methods to improve radiosensitivity (VEGF/PDGF inhibitors) [10, 36] and taxane combination trials (CALGB 90401, VITAL I and ASCENT 2 [Table 1]). Multiple gene therapies include the use of numerous histone deacetylase by acetylation inhibitors (HDACs) (Table 1) or a double suicide gene (Ad5-CD/Tkrep [replication-competent adenovirus to $\mathrm{CD} / \mathrm{HSV}$-tk]) with prodrugs fluorouracil and ganciclovir (5-FC/GCV) [48]. In phase I trials using a trimodal therapy (double suicide gene, $5-\mathrm{FC} / \mathrm{GCV}$ plus radiotherapy), PSA levels were reduced to $<0.5 \mathrm{ng} \mathrm{mL}^{-1}$ in 5 out of 10 patients over 9 months [49]. In androgenindependent disease, in vivo studies using PSA/PSMApositive PCa cells have also shown therapeutic benefits by combining GCV with AdIU1 (a prostate-restricted replicative adenovirus [PRRA] combined with HSV-TK)
[50]. Suicide gene therapy has also been monitored with a combination approach including non-invasive imaging using the NIS [51]. A replication-competent Ad combined with two suicide genes and the NIS gene (Ad5-yCD/ utTK(SR39)rep-hNIS/) was injected intra-prostatically into men with localized PCa. NIS gene expression (GE) was imaged using single-photon emission-computed tomography (SPECT). GE volume seemed to change over time, peaking at 1-2 days after injection. There was no evidence of extra-prostatic Ad activity seen on SPECT.

\section{Conclusion}

The advent of new molecular markers and advances in imaging techniques offers the potential to more accurately measure responses, predicts prognosis and directs therapy. Significant progress has been made in PCa gene therapy and immunomodulation. However, the long-term effects and benefits on overall survival remain to be determined. There is a growing interest in the use of molecular markers in chemoprevention with $\mathrm{PCa}$ vaccines targeting early $\mathrm{PCa}$, and this strategy is potentially feasible [43]. A number of studies are currently entering Phase III trials and offer potential therapeutic options for patients with HRPC, especially for those who have failed taxane treatment. Promising markers for therapeutic targeting include OC, growth factors, PAP, PSMA and PSA. The results of larger multi-centre controlled trials are critical to help direct the future of these therapeutic options.

\section{References}

1 Smaletz O, Scher HI, Small EJ, Verbel DA, McMillan A, et al. Nomogram for overall survival of patients with progressive metastatic prostate cancer after castration. J Clin Oncol 2002; 20: 3972-82.

2 Hussain A, Dawson NA. Chemotherapy in hormone resistant prostate cancer. In: Basow DS, editor. UpToDate. Waltham, MA: UpToDate; 2008.

3 Dunsmuir WD, Gillett CE, Meyer LC, Young MP, Corbishley C, et al. Molecular markers for predicting prostate cancer stage and survival. BJU Int 2000; 86: 869-78.

4 Hällström TM, Laiho M. Genetic changes and DNA damage responses in the prostate. Prostate 2008 ; 68: 902-18.

5 Marrocco DL, Tilley WD, Bianco-Miotto T, Evdokiou A, Scher HI, et al. Suberoylanilide hydroxamic acid (vorinostat) represses androgen receptor expression and acts synergistically with an androgen receptor antagonist to inhibit prostate cancer cell proliferation. Mol Cancer Ther 2007; 6: 51-60.

6 Lawson DA, Witte ON. Stem cells in prostate cancer initiation and progression. J Clin Invest 2007; 117: 2044-50.

7 Wang S, Gao J, Lei Q, Rozengurt N, Pritchard C, et al. Prostate-specific deletion of the murine Pten tumor suppressor gene leads to metastatic prostate cancer. Cancer Cell 2003; 4: 209-21.

8 Vaughn DJ, Brown AW Jr, Harker WG, Huh S, Miller L, et al. Multicenter Phase II study of estramustine phosphate plus weekly paclitaxel in patients with androgen-independent prostate carcinoma. Cancer 200415; 100: 746-50.

9 Moon C, Park JC, Chae YK, Yun JH, Kim S. Current status of experimental therapeutics for prostate cancer. Cancer Lett 2008; 266: $116-34$ 
10 Walczak JR, Pili R, Carducci MA. Novel and emerging treatment techniques in prostate cancer. In: Basow DS, editor. UpToDate. Waltham, MA: UpToDate; 2008.

11 Pelengaris S, Khan M, Evan G. c-MYC: more than just a matter of life and death. Nat Rev Cancer 2002; 2: 764-76.

12 Balaji KC, Koul H, Mitra S, Maramag C, Reddy P, et al. Antiproliferative effects of c-myc antisense oligonucleotide in prostate cancer cells: a novel therapy in prostate cancer. Urology 1997; 50: 1007-15.

13 Steiner MS, Anthony CT, Lu Y, Holt JT. Antisense c-myc retroviral vector suppresses established human prostate cancer. Hum Gene Ther 1998; 9: 747-55.

14 Dawson NA. New molecular targets in advanced prostate cancer. Expert Rev Anticancer Ther 2006; 6: 993-1002.

15 Froehner M, Hakenberg OW, Wirth MP. Molecular therapy in urologic oncology. Urol Int 2007; 79: 1-7.

16 Carducci MA, Jimeno A. Targeting bone metastasis in prostate cancer with endothelin receptor antagonists. Clin Cancer Res 2006; 12: 6296s-6300s.

17 Carducci MA, Saad F, Abrahamsson PA, Dearnaley DP, Schulman $\mathrm{CC}$, et al. A phase 3 randomized controlled trial of the efficacy and safety of atrasentan in men with metastatic hormone-refractory prostate cancer. Cancer 2007; 110: 1959-66.

18 De Miguel P, Royuela, Bethencourt R, Ruiz A, Fraile B, et al. Immunohistochemical comparative analysis of transforming growth factor alpha, epidermal growth factor, and epidermal growth factor receptor in normal, hyperplastic and neoplastic human prostates. Cytokine 1999; 11: 722-7.

19 Golias Ch, Charalabopoulos A, Stagikas D, Giannakopoulos X, Peschos $\mathrm{D}$, et al. Molecular profiling and genomic microarrays in prostate cancer. Exp Oncol 2007; 29: 82-4.

20 Eeles RA, Kote-Jarai Z, Giles GG, Olama AA, Guy M, et al. Multiple newly identified loci associated with prostate cancer susceptibility. Nat Genet 2008; 40: 316-21.

21 Wagenlehner FM, Elkahwaji JE, Algaba F, Bjerklund-Johansen $\mathrm{T}$, Naber KG, et al. The role of inflammation and infection in the pathogenesis of prostate carcinoma. BJU Int 2007; 100: 733-7.

22 Figueiredo ML, Kao C, Wu L. Advances in preclinical investigation of prostate cancer gene therapy. Mol Ther 2007; 15: 1053-64.

23 Matsubara S, Wada Y, Gardner TA, Egawa M, Park MS, et al.. A conditional replication-competent adenoviral vector, Ad-OC-E1a, to cotarget prostate cancer and bone stroma in an experimental model of androgen-independent prostate cancer bone metastasis. Cancer Res 2001; 61: 6012-9.

24 Shirakawa T, Terao S, Hinata N, Tanaka K, Takenaka A, et al. Long-term outcome of phase I/II clinical trial of Ad-OC-TK/VAL gene therapy for hormone-refractory metastatic prostate cancer. Hum Gene Ther 2007; 18: 1225-32.

25 Horoszewicz JS, Kawinski E, Murphy GP. Monoclonal antibodies to a new antigenic marker in epithelial prostatic cells and serum of prostatic cancer patients. Anticancer Res 1987; 7: 927-35.

26 Singh D, Febbo PG, Ross K, Jackson DG, Manola J, et al. Gene expression correlates of clinical prostate cancer behavior. Cancer Cell 2002; 1: 203-9.

27 Mathew P, Thall PF, Jones D, Perez C, Bucana C, et al. Plateletderived growth factor receptor inhibitor imatinib mesylate and docetaxel: a modular phase I trial in androgen-independent prostate cancer. J Clin Oncol 2004; 22: 3323-9.

28 McNeal JE. Origin and evolution of benign prostatic enlargement Invest Urol 1978; 15: 340-5.

29 De Marzo AM, Marchi VL, Epstein JI, Nelson WG. Proliferative inflammatory atrophy of the prostate: implications for prostatic carcinogenesis. Am J Pathol 1999; 155: 1985-92.

30 Isaacs W, De Marzo A, Nelson WG. Focus on prostate cancer. Cancer Cell 2002; 2: 113-6.

31 Bauer JJ, Sesterhenn IA, Mostofi KF, McLeod DG, Srivastava S, et al. p53 nuclear protein expression is an independent prognostic marker in clinically localized prostate cancer patients undergoing radical prostatectomy. Clin Cancer Res 1995; 1: 1295-300.

32 Malins DC, Johnson PM, Barker EA, Polissar NL, Wheeler TM, et al. Cancer-related changes in prostate DNA as men age and early identification of metastasis in primary prostate tumors. Proc Natl Acad Sci USA 2003; 100: 5401-6.

33 Ramírez ML, Nelson EC, Evans CP. Beyond prostate-specific antigen: alternate serum markers. Prostate Cancer Prostatic Dis 2008; 11: 216-29.

34 Cerveira N, Ribeiro FR, Peixoto A, Costa V, Henrique R, et al. TMPRSS2-ERG gene fusion causing ERG overexpression precedes chromosome copy number changes in prostate carcinomas and paired HGPIN lesions. Neoplasia 2006; 8: 826-32.

35 Chan N, Milosevic M, Bristow RG. Tumor hypoxia, DNA repair and prostate cancer progression: new targets and new therapies. Future Oncol 2007; 3: 329-41.

36 Timke C, Zieher H, Roth A, Hauser K, Lipson KE, et al. Combination of vascular endothelial growth factor receptor/plateletderived growth factor receptor inhibition markedly improves radiation tumor therapy. Clin Cancer Res 2008; 14: 2210-9.

37 Berry W, Eisenberger M. Achieving treatment goals for hormonerefractory prostate cancer with chemotherapy. Oncologist 2005; 10: 30-9.

38 Palayoor ST, Mitchell JB, Cerna D, Degraff W, John-Aryankalayil M, et al. PX-478, an inhibitor of hypoxia-inducible factor-1alpha, enhances radiosensitivity of prostate carcinoma cells. Int J Cancer 2008; 123: 2430-7.

39 Herman JR, Adler HL, Aguilar-Cordova E, Rojas-Martinez A, Woo $\mathrm{S}$, et al. In situ gene therapy for adenocarcinoma of the prostate: a phase I clinical trial. Hum Gene Ther 1999; 10: 1239-49.

40 Thompson IM, Goodman PJ, Tangen CM, Lucia MS, Miller GJ, et al. The influence of finasteride on the development of prostate cancer. N Engl J Med 2003; 349: 215-24.

41 Gomella LG. Chemoprevention using dutasteride: the REDUCE trial. Curr Opin Urol 2005; 15: 29-32.

42 Crawford ED. Chemoprevention strategies in prostate cancer. In Basow DS, editor. UpToDate. Waltham, MA: UpToDate; 2008.

43 Garcia-Hernandez Mde L, Gray A, Hubby B, Klinger OJ, Kast WM. Prostate stem cell antigen vaccination induces a long-term protective immune response against prostate cancer in the absence of autoimmunity. Cancer Res 2008; 68: 861-9.

44 Nasu Y, Saika T, Ebara S, Kusaka N, Kaku H, et al. Suicide gene therapy with adenoviral delivery of HSV-tK gene for patients with local recurrence of prostate cancer after hormonal therapy. Mol Ther 2007; 15: 834-40.

45 Lipinski KS, Pelech S, Mountain A, Irvine AS, Kraaij R, et al. Nitroreductase-based therapy of prostate cancer, enhanced by raising expression of heat shock protein 70, acts through increased anti-tumour immunity. Cancer Immunol Immunother 2006; 55: 347-54.

46 Rini BI, Small EJ. The potential for prostate cancer immunotherapy. Crit Rev Oncol Hematol 2003; 46: S117-25.

47 Lin AM, Hershberg RM, Small EJ. Immunotherapy for prostate cancer using prostatic acid phosphatase loaded antigen presenting cells. Urol Oncol 2006; 24: 434-41.

48 Freytag SO, Khil M, Stricker H, Peabody J, Menon M, et al. Phase I study of replication-competent adenovirus-mediated double suicide gene therapy for the treatment of locally recurrent prostate cancer. Cancer Res 2002; 62: 4968-76.

49 Freytag SO, Stricker H, Pegg J, Paielli D, Pradhan DG, et al. Phase I study of replication-competent adenovirus-mediated doublesuicide gene therapy in combination with conventional-dose threedimensional conformal radiation therapy for the treatment of newly diagnosed, intermediate- to high-risk prostate cancer. Cancer Res 2003; 63: 7497-506.

50 Ahn M, Lee SJ, Li X, Jiménez JA, Zhang YP, et al. Enhanced combined tumor-specific oncolysis and suicide gene therapy for prostate cancer using M6 promoter. Cancer Gene Ther 2008 Sep 5. Epub ahead of print.

51 Barton KN, Stricker H, Brown SL, Elshaikh M, Aref I, et al. Phase I study of noninvasive imaging of adenovirus-mediated gene expression in the human prostate. Mol Ther 2008; 16: 1761-9. 